\title{
Appendix 2: Delphic Citizens Attested as Proxenoi of Other Cities and States
}

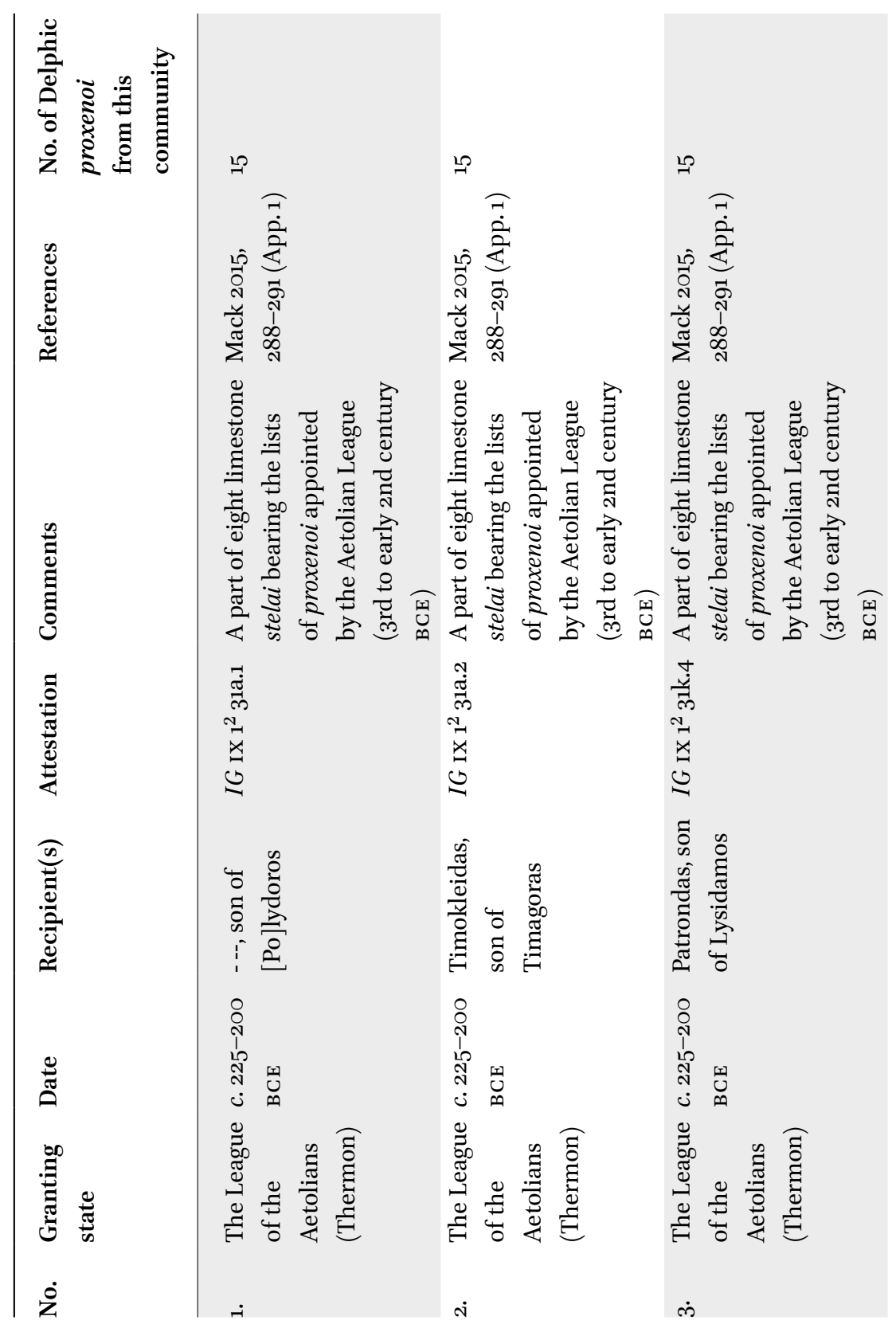




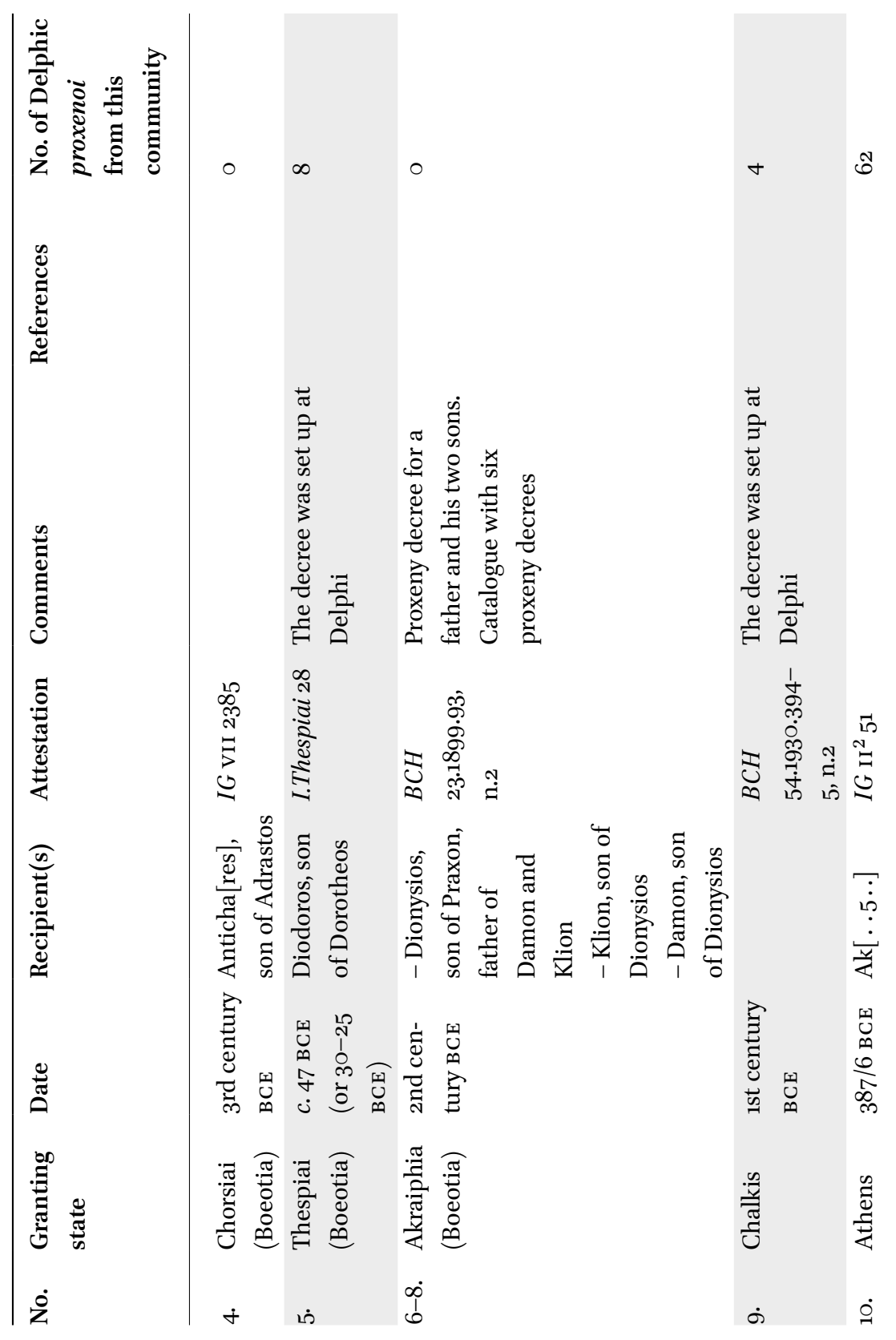




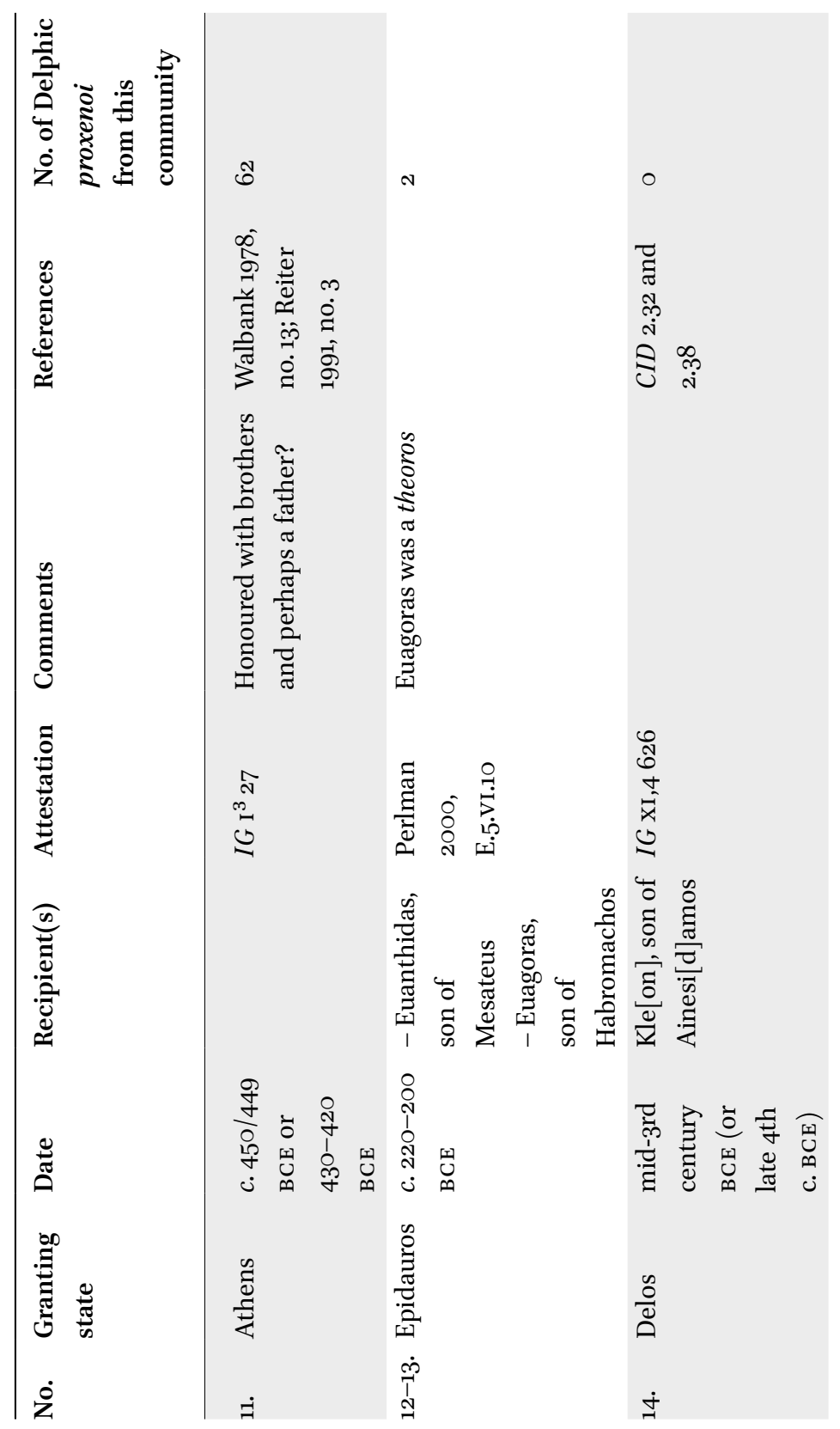




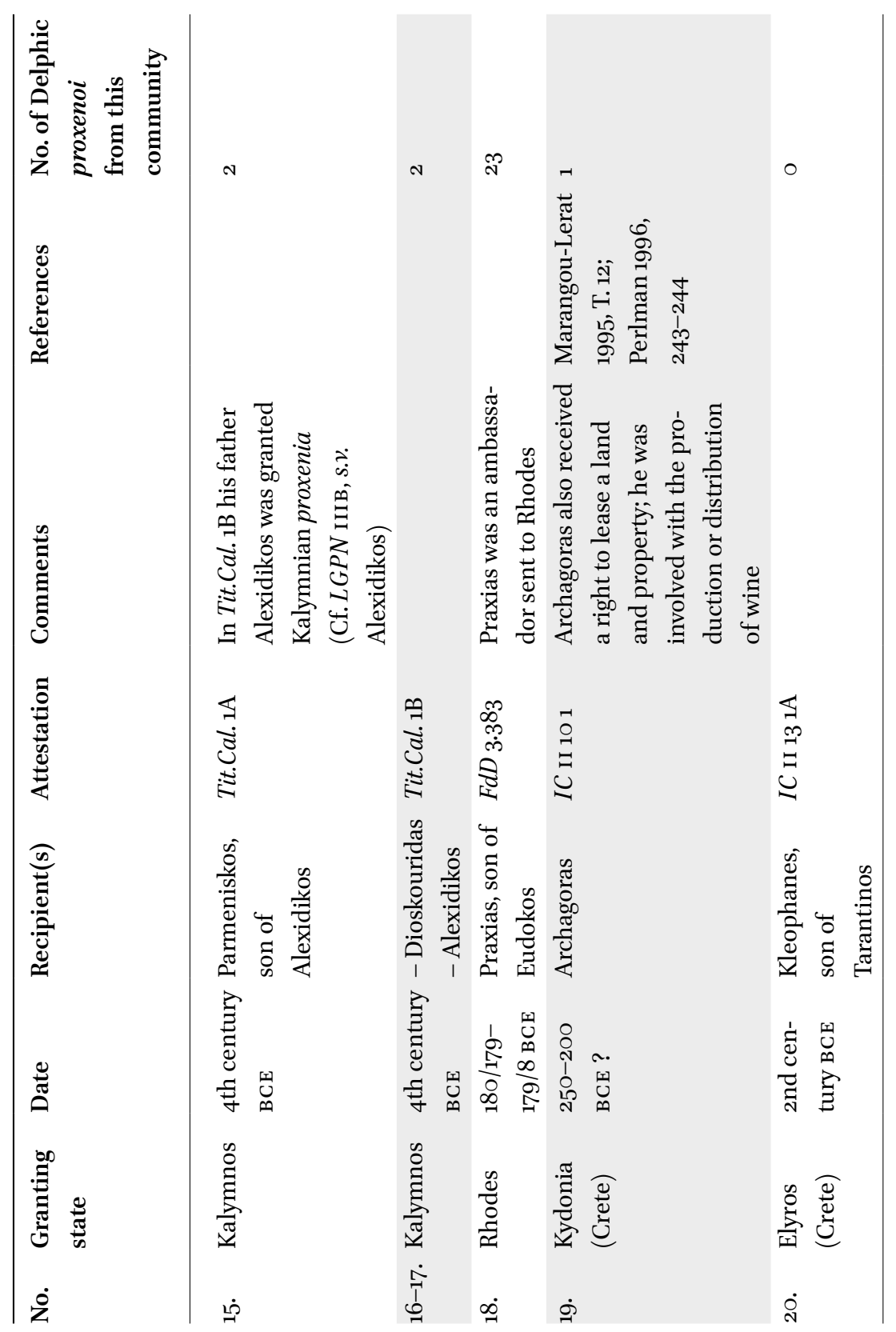

